\title{
Rheumatological Manifestations in HIV-Positive Patients: A Single-Center Study
}

\author{
Renu Saigal (D) - Avik Chakraborty - Ram Narayan Yadav • \\ Laxmi Kant Goyal
}

Received: July 23, 2020 / Published online: August 24, 2020

(c) The Author(s) 2020

\section{ABSTRACT}

Introduction: Rheumatological manifestations (RM) are very common in human immunodeficiency virus (HIV)-infected patients. The aim of this study was to determine the clinical spectrum of musculoskeletal involvement and relationship with the Centers for Disease Control and Prevention (CDC) stage and CD4+ cells and other factors.

Methods: A cross-sectional study was conducted involving 75 patients of over 18 years of either sex with confirmed HIV status attending a tertiary care hospital in north India in one calendar year. Baseline demographic details, relevant history including duration of

Digital Features To view digital features for this article go to https://doi.org/10.6084/m9.figshare.12789584.

R. Saigal

Department of Medicine, JNU IMSRC Medical

College, Jaipur, India

A. Chakraborty

Department of Medicine, TMC and Dr. BRAM

Teaching Hospital, Hapania, Agartala, India

R. N. Yadav

Department of Medicine, SMS Medical College, Jaipur, Rajasthan, India

L. K. Goyal ( $\square)$

Geriatric Medicine, SMS Medical College, Jaipur,

Rajasthan, India

e-mail: drlkgoyal@gmail.com combination antiretroviral therapy (cART), RM, joints involved, CD4 cell count, and biochemical parameters were evaluated.

Results: Of 75 patients, 54 were male and 21 were female (mean age $33.15 \pm 5.00$ years, range 21-48 years). Most common RM was arthralgia (26.67\%), followed by myalgia $(18.67 \%)$, and arthritis (13.33\%). Keratoderma blennorrhagicum $(1.33 \%)$, tendo-achilles tendinitis $(2.67 \%)$, and plantar fasciitis $(2.67 \%)$ were other manifestations. Spondyloarthritis (SpA) was seen in $8 \%$ patients (undifferentiated SpA $4 \%$, reactive arthritis $2.67 \%$, psoriatic arthritis $1.67 \%$ ). HIVassociated arthritis was seen in $2.67 \%$ while septic arthritis, rheumatoid arthritis, vasculitis, and diffuse infiltrative lymphocytic syndrome were seen in one patient (1.33\%) each. The mean duration of disease in patients with RM was significantly less than patients without RM $(p<0.01)$. The erythrocyte sedimentation rate in patients with RM was significantly higher than in patients without RM $(p<0.05)$. Mean CD4 + cells were also significantly lower in patients with RM as compared to patients without RM $(p<0.05)$. Significantly fewer patients on cART had RM in comparison to patients not on cART $(\mathrm{p}<0.001)$. Of 35 patients with RM, 25 were in CDC stage IV.

Conclusion: RM are common in HIV-infected patients. HIV arthralgia, myalgia, and undifferentiated SpA are the common manifestations. $\mathrm{RM}$ were associated with low CD4 counts. Most of the cases with RM were in CDC stage IV. 
Keywords: AIDS; Arthralgia; HIV; Rheumatological manifestations; Rheumatology

\section{Key Summary Points}

Human immunodeficiency virus (HIV) infection is common in India.

Rheumatological manifestations (RM) are very common in HIV-infected patients.

This study determines the clinical spectrum of musculoskeletal involvement and relationship with the CDC stage and CD4+ cells and other factors in HIV patients.

HIV-associated arthralgia was the most common rheumatological manifestation in patients with HIV. Myalgia and arthritis were some of the other common manifestations.

Spondyloarthritidies ( $\mathrm{SpA})$ is the commonest type of arthritis.

Low CD4 cell count and patients not taking combination antiretroviral therapy (cART) were independently associated with RM. cART started early in HIV patients may halt the progression of RM.

\section{INTRODUCTION}

Human immunodeficiency virus (HIV) causing acquired immunodeficiency syndrome (AIDS) is a common disease that is characterized by initial mild symptoms, progressively involving multiple organs of the body, suppressing the immune system, and causing depletion of CD4+ cells. Globally, 37.9 million people were reported to have HIV up to the end of 2018 [1]. Patients with HIV are highly prone to various opportunistic infections, and neurologic, inflammatory, or musculoskeletal diseases [2].

The increasing burden of rheumatological diseases in these patients can cause complications with increased risk of morbidity.
Therefore, early identification of these manifestations is important for better management strategies.

The prevalence of HIV in India is about $(0.2 \%)$, and India has the third-largest HIV epidemic in the world, with 2.1 million people living with HIV [3].

There are many rheumatological manifestations (RM) in HIV patients that can occur at any stage of the disease. Winchester et al. described the RM in HIV patients for the first time [4].

Arthralgia, HIV-associated arthritis, reactive arthritis, undifferentiated spondyloarthritis (SpA), septic arthritis, osteomyelitis, myalgia, polymyositis, dermatomyositis, diffuse infiltrative lymphocytosis syndrome (DILS), vasculitis, etc., are the various RM described in HIV patients $[5,6]$.

Various studies have shown $2-71.3 \%$ of patients with HIV may have RM, with arthralgia being the commonest manifestation, seen in $25-40 \%$ of patients [7-9].

This study was undertaken to assess the spectrum and the pattern of involvement in HIV patients, and the relationship with the Centers for Disease Control and Prevention (CDC) stage and CD4+ cells and other factors.

\section{METHODS}

This cross-sectional study was undertaken to describe the spectrum of RM in HIV patients. All eligible patients admitted to medical wards, attending the ART clinic, the medical outpatient department, and the rheumatology clinic of the SMS Medical College, Jaipur, Rajasthan, India, in one calendar year were included consecutively in this prospective study. The study was approved by the institutional research review board (post-graduate research review board of SMS Medical College, Jaipur, India), and was conducted following the approved protocol and ethical principles that have their origin in the Declaration of Helsinki. Written informed consent was obtained from each patient before enrolment.

Seventy-five cases were enrolled and a sample of this size was adequate at 95\% confidence 
and $12 \%$ absolute error to verify the expected $40-72 \%$ RM in HIV patients. [6, 10].

Baseline demographic details, history of present illness, history of the high risk of sexual behavior, intravenous drug abuse, blood or blood product transfusion, organ transplantation, drug history, duration of combination antiretroviral therapy (cART), and details of biochemical parameters, including complete blood count, erythrocyte sedimentation rate (ESR), c-reactive protein (CRP), rheumatoid factor (RF), antinuclear antibody (ANA), venereal disease research laboratory test (VDRL), and uric acid were noted. The CD4 cell count and detailed rheumatological examination were performed to note the joints involved, the number of swollen joints, joint tenderness, deformities, range of movement, evidence of synovitis, and investigations. According to the CDC, patients were classified as class I (initial infection with the virus and development of antibodies), II (asymptomatic carrier state), III (AIDS-related complex), and IV (AIDS). [2]

Diagnosis of rheumatic disease was made using established American College of Rheumatology criteria. (Available at https:// www.rheumatology.org/Practice-Quality/Clini cal-Support/Criteria).

Patients with conditions such as diabetes and hypothyroidism, those with a positive titer of hepatitis B surface antigen and immunodeficiency states (other than HIV), or drowsy and unconscious patients were excluded from the study, as RM in these diseases might have confounded our observations.

\section{RESULTS}

Out of 75 patients, 54 were male and 21 were female. The mean age of the patients studied was $33.15 \pm 5.00$ years (range 21-48 years) (Table 1).

Most of the patients (89.33\%) acquired HIV infection by sexual contact, one (1.33\%) patient had homosexual contact, while $4 \%$ gave a history of blood transfusion, and the cause was not apparent in the rest. There was no case of HIV transmission by intravenous drug abuse.
Thirty-five patients ( 25 male and 10 female) had RM (46.67\%), with no significant association of RM and sex. Most of the patients $(n=18$; $24 \%$ ) were from the age group 31-40 years followed by patients $(n=15 ; 20 \%)$ of $21-30$ years (Table 1). The mean age of patients with RM was $33.08 \pm 5.08$ years. No significant difference was found in the age of patients with or without RM.

ESR was significantly higher in patients with $\mathrm{RM}(76.28 \pm 29.45)$ compared to patients without $\mathrm{RM} \quad(60.62 \pm 36.29) \quad(p<0.05)$ (Table 1). The CD4 count was significantly lower in patients with RM compared to patients without RM $(p<0.05)$ (Table 1$)$.

The CD4+ count was significantly lower in patients with RM compared to patients without RM $(p<0.05 \%)$ (Table 1$)$. Only 6 patients on cART had RM compared to 29 patients who had RM but were not on cART (Table 1). The association between cART and RM was found to be statistically significant $(p<0.001)$.

Twenty-five patients with RM were in CDC stage IV, with 8 and 2 in CDC stage III and II, respectively (Table 1 ).

Various RM, rheumatic disease entities, and biochemical investigations are shown in Table 2. RF was present in 2 patients (2.67\%), 1 patient had typical rheumatoid arthritis, ANA was present in 6 patients (8\%), while none of the patients had systemic lupus erythematosus (SLE) or other features of connective tissue disease, and it was thought to be false positive as the ENA profile was also negative. Hyperuricemia was seen in 8 patients but none had gouty arthritis (Table 2).

\section{DISCUSSION}

Multiple RM have been reported in HIV patients in various studies. RM were seen in 35 (46.67\%) patients in the present study, and RM in HIV varied in different studies ranging from 2-71.3\% [6-9, 12-14]. Reports from France and Spain have shown a low prevalence of RM in HIV patients $[15,16]$.

RM may occur because of the viral infection itself, the activation of $B$ cells and subsequent circulating immune complexes, auto- 
Table 1 Characteristics of study participants

\begin{tabular}{llll}
\hline & RM present $\boldsymbol{N}$ 35 & RM absent $\boldsymbol{N}$ 40 & $p$ \\
\hline Age group (years) & & & \\
$21-30$ & $15(20 \%)$ & $15(20 \%)$ & \\
$31-40$ & $18(24 \%)$ & $20(26.67 \%)$ & \\
$41-50$ & $2(2.67 \%)$ & $5(6.67 \%)$ & $<0.01$ \\
Duration of HIV (month), mean (SD) & $8.20 \pm 7.96$ & $14.90 \pm 15.34$ & $<0.05$ \\
ESR (mm/1st hour), mean (SD) & $76.28 \pm 29.45$ & $60.62 \pm 36.29$ & $>0.05$ \\
Uric acid (mg/dL), mean (SD) & $4.86 \pm 1.38$ & $4.44 \pm 1.52$ & $<0.05$ \\
CD4 (cells/cu.mm), mean (SD) & $179.17 \pm 154.36$ & $267.57 \pm 177.78$ & $<0.001$ \\
Treatment & & & \\
cART & $6(8 \%)$ & $26(34.67 \%)$ & \\
Non-cART & $29(38.67 \%)$ & $14(18.67 \%)$ & \\
CDC Stage & & $8(12.67 \%)$ & \\
II & $2(2.67 \%)$ & $12(16 \%)$ & \\
III & $8(10.67 \%)$ & $20(26.67 \%)$ & \\
IV & $25(33.33 \%)$ & & \\
\hline
\end{tabular}

$H I V$ Human immunodeficiency virus, ESR erythrocyte sedimentation rate, $C D C$ Centers for Disease Control and Prevention

antibodies, hypergammaglobulinemia, a switch from Th1 to Th2, and subsequent increased expression and release of cytokines, environmental factors like infection with arthritogenic microorganisms, opportunistic infections, the medication used, or malignancy [17].

In contrast to studies from the western part of the globe where there have been a large number of patients with HIV infection through IV drug abuse or homosexual contact, our study had only one patient giving the history of homosexual contact. $[6,18,19]$.

The mean duration of patients presenting with RM and patients without RM in HIV cases since the diagnosis was $8.20 \pm 7.96$ and $14.90 \pm 15.34$ months, respectively, which was statistically significant $(p<0.01)$ (Table 1$)$, as patients with RM because of their symptoms and RM presented earlier than the patients without RM.
Arthralgia was the most common manifestation seen in 20 patients $(26.67 \%)$ followed by myalgia seen in 14 patients (18.67\%), and arthritis in 10 patients (13.33\%) (Table 2). In many of the studies, arthralgia was the commonest symptom among HIV patients. $[5,6,14,20-22]$. Arthralgia was seen mainly in knee joints (10 cases) followed by shoulders (5), elbows (4), ankles (3), wrists (2), and the small joints of hands and feet in 1 case each. It was intermittent in 17 patients and persistent in 3 patients, and was oligoarticular, polyarticular, and monoarticular in 11,5 , and 4 cases, respectively. Similar findings have been observed in other studies $[5,22]$, while in another study only $2 \%$ of patients had arthralgia [21].

Myalgia was seen in 14 patients (18.66\%), but only severe muscle pains were included in our study. Three patients were on zidovudine therapy and in one patient myalgia responded 
Table 2 Rheumatological manifestations $(R M)$, rheumatic diseases and biochemical characteristics in HIV-positive patients

\begin{tabular}{|c|c|c|}
\hline Clinical RM & $\begin{array}{l}\text { Number of } \\
\text { patients }\end{array}$ & $(\%)$ \\
\hline Arthritis & 10 & 13.33 \\
\hline Arthralgia & 20 & 26.67 \\
\hline Myalgia & 14 & 18.67 \\
\hline Psoriasis & 02 & 2.67 \\
\hline $\begin{array}{l}\text { Keratoderma } \\
\text { blenorrhagicum }\end{array}$ & 01 & 01.33 \\
\hline Tendo-achillesenthesitis & 02 & 2.67 \\
\hline Plantar fasciitis & 02 & 2.67 \\
\hline \multicolumn{3}{|l|}{ Rheumatic disease } \\
\hline SpA & 06 & 08.00 \\
\hline Reactive & 02 & 02.67 \\
\hline Undifferentiated SpA & $\mathrm{O} 3$ & 04.00 \\
\hline Psoriatic arthritis & 01 & 1.33 \\
\hline HIV-associated arthralgia & 20 & 26.67 \\
\hline HIV-associated arthritis & 02 & 02.67 \\
\hline Septic arthritis & 01 & 01.33 \\
\hline Rheumatoid arthritis & 01 & 01.33 \\
\hline DILS & 01 & 01.33 \\
\hline Vasculitis & 01 & 01.33 \\
\hline \multicolumn{3}{|l|}{ Biochemical investigations } \\
\hline $\mathrm{CRP}(>6 \mathrm{mg} / \mathrm{L})$ & 62 & $82.67 \%$ \\
\hline $\mathrm{RF}$ & 02 & $2.67 \%$ \\
\hline ANA & 06 & $08.00 \%$ \\
\hline VDRL & 04 & $05.33 \%$ \\
\hline $\operatorname{ESR}(>20 \mathrm{~mm} / \mathrm{hr})$ & 64 & $85.33 \%$ \\
\hline $\begin{array}{l}\text { Hyperuricemia } \\
(>7 \mathrm{mg} \%)\end{array}$ & 08 & $10.67 \%$ \\
\hline
\end{tabular}

SpA Spondyloarthritis, $H I V$ human immunodeficiency virus, DILS diffuse infiltrative lymphocytosis syndrome, $C R P$ c-reactive protein, $R F$ rheumatoid factor, $A N A$ antinuclear antibody, $V D R L$ venereal disease research laboratory test, $E S R$ erythrocyte sedimentation rate to zidovudine withdrawal. In other studies, the prevalence of myalgia was less i.e. $10 \%$ and $14 \%$, respectively $[6,24]$, while Buskila et al. found myalgia in $35 \%$ of patients [25].

Arthritis was seen in 10 patients (13.33\%), affecting the knee joints in 10 , ankles in 6 , proximal interphalangeal joints in 4 , wrists in 3 , metatarsophalangeal joints in 2 , and distal interphalangeal joints in 1 . Arthritis prevalence varied, being more in a few studies [5, 6, 22, 25], but less in others $[24,26]$.

HIV arthritis was seen in 2 patients, one of which had oligoarthritis involving left knee and ankle, while the other had symmetrical polyarthritis of wrists, elbows, knees and ankle joints with acute onset and remission in 4-6 weeks; RF and HLA B27 were negative and sacroiliac joints were normal on imaging, and it was non-erosive. This entity, HIV arthritis, has been described by Reville et al. [27]. Both patients were in CDC stage IV. The prevalence of HIV arthritis was less than reported in other studies $[6,11,21]$.

One patient with typical polyarthritis and with RF positive was found in our study, presented in CDC stage III, and was not on cART. Similar findings have been reported by other authors [11]. A few authors found in their studies that rheumatoid arthritis (RA) and SLE may remit with HIV disease, but RA can coexist with HIV infection [27].

SpA was the most frequent arthritides, observed in 6 patients (8\%) in the present study. Undifferentiated SpA (USpA) was seen in 3 cases (4\%) (Table 2). Spondyloarthritidies are frequently observed in HIV-positive patients. [7, 11, 12, 22, 29-31].

Reactive arthritis was the second most common SpA, seen in 2 cases $(2.67 \%)$, both patients having a history of dysentery 1 month before onset. One patient presented with keratoderma blennorrhagicum, plantar fasciitis, and bilateral knee joint and right ankle joint arthritis, while a second patient had asymmetric additive involvement of both ankle joints, plantar fasciitis, and conjunctivitis. Both the patients were in CDC stage IV.

Reactive arthritis, often severe, progressive, and refractory to treatment, was the commonest RM seen in HIV infection [31, 32]. 
The association between HIV infection and Reiter's syndrome might be explained by the severe immunosuppression, which predisposes them to the presence of arthritogenic microorganisms, e.g., Shigella spp, Chlamydia trachomatis, Entamoeba histolytica, Giardia lamblia, Cryptosporidium spp., Isospora belli, Candida spp, and Cytomegalovirus [33].

One patient of PsA $(1.33 \%)$ was seen who had asymmetrical oligoarthritis involving the right knee, the 3rd, and 4th proximal and distal interphalangeal joints, pitting of nails with typical psoriatic skin rash of 7 months duration and was in CDC IV stage.

SpA, ReA, and PsA in HIV are mediated by an intact immune system, i.e., CD8 system in HIV.

DILS was seen in one patient, who had parotid and submandibular gland enlargement with xerostomia of 6 months duration. On parotid biopsy, lymphocytic infiltration was seen. The patient was not on cART. Since the advent of cART, the prevalence of DILS has markedly decreased. It occurs because of CD8+ cell infiltration in parotid glands, and is a unique syndrome of HIV [5, 22]. Indeed, DILS, HIV-associated arthritis, and painful articular syndromes are all unique to HIV [34].

Septic arthritis was seen in just one patient (Table 2) in CDC stage IV and was due to Staphylococcal aureus. This infection has been shown to be a known cause of septic arthritis in many studies [21, 35]. Septic complications were the most common manifestations seen in $41 \%$ of patients in one study [36]. Low prevalence of septic arthritis in our study may be because no patient had HIV transmission because of IV drug abuse. In other studies, IV drug abuse was a frequent mode of transmission of HIV, and these studies showed a high prevalence of infective complications in their studies.

Vasculitis was seen in one patient, with palpable purpura seen in lower limbs. The patient had negative ANA and, on biopsy, leukocytoclastic vasculitis.

ESR was raised significantly in patients with $\mathrm{RM}$ as compared to patients without RM $(p<0.05)$ (Table 1$)$. Only 6 patients on cART had RM, and cART has been shown to improve arthritis due to HIV (Table 1) [37].
RF was positive in two patients in our study, one who had a clinical picture of RA while in the second patient no rheumatic disease was found (Table 2). ANA was seen in 6 patients but features of connective tissue disease were absent and the ENA profile was also negative (Table 2). RF and ANA positivity has also been found in other studies [5, 11, 21]. Different auto-antibodies have been described in HIV patients without any feature of connective tissue disease, which may reflect polyclonal B cell activation and hypergammaglobulinemia [33].

VDRL was also positive in 4 patients (Table 2) without any clinical feature of syphilis. In $40-50 \%$ patients with HIV, false positive tests of syphilis have been seen in various studies $[11,33]$.

In the present study, asymptomatic hyperuricemia (HU) was seen in 8 (10.67\%) patients, although mean uric acid in patients with RM and without RM did not differ. No patient had gouty arthritis and the cause of $\mathrm{HU}$ was not apparent. HU has also been described in $41 \%$ of patients of HIV patients which was related to malignancy [5].

In the present study, CD4+ cells were significantly lower in patients with RM in comparison to patients without RM (Table 1), and low CD4 counts were not associated with infections but were present with RM. This finding was unique, as in one study correlation was found between osteoarticular infections and low CD4 counts $(<200)$, and pyomyositis and lymphoma appeared when CD4 was $<150$ [18]. In other studies, no correlation was found between CD4 count and RM [21].

In the present study, 25 patients with RM were seen in CDC stage IV, while 8 and 2 patients were in CDC stages III and II, respectively (Table 1). Other studies also had a similar observation that the prevalence of RM increases in later stages of HIV $[17,39,40]$.

In another study by Berman et al., $57 \%$ of patients with RM were in stage IV [40].

A comparison of a few studies and the present study is shown in Table 3.

Limitations of the current study: This study was conducted during one calendar year so the number of participants recruited in this study were small, but this small sample meets the 


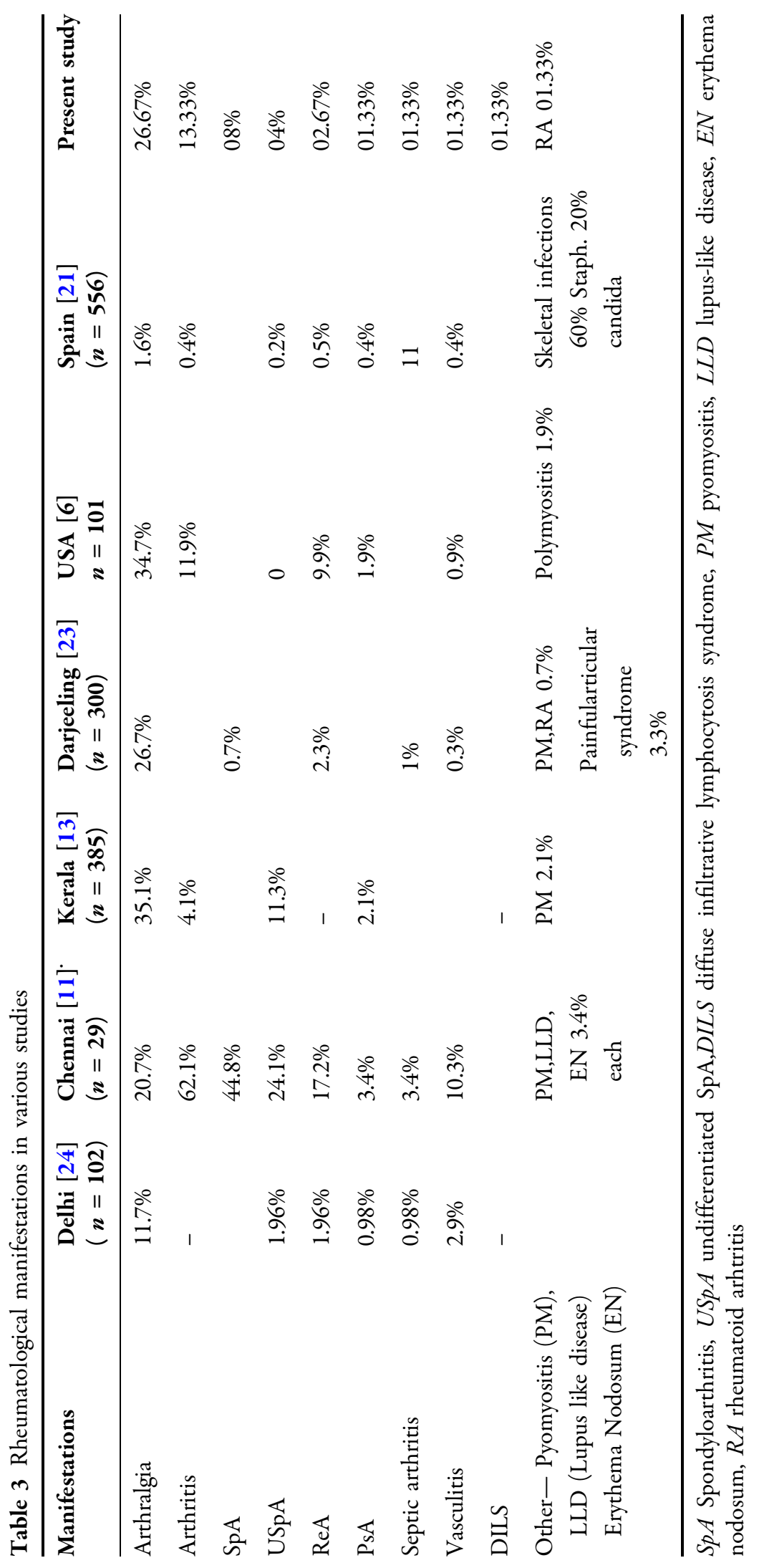


statistical criteria for sample size (vide supra). This study was a single-center study so the results may not represent the general population.

\section{CONCLUSION}

HIV-associated arthralgia was the most common rheumatological manifestation in patients with HIV. However, myalgia and arthritis were among other common manifestations. SpA was the commonest type of arthritis. Low CD4 cell count and patients not taking cART were independently associated with RM. cART started early in HIV patients may halt the progression of RM.

\section{ACKNOWLEDGEMENTS}

We thank the participants of the study.

Funding. No funding or sponsorship was received for this study or publication of this article.

Authorship. All named authors meet the International Committee of Medical Journal Editors (ICMJE) criteria for authorship for this article, take responsibility for the integrity of the work as a whole, and have given their approval for this version to be published.

Disclosures. Renu Saigal, Avik Chakraborty, Ram Narayan Yadav, and Laxmikant Goyal have nothing to disclose.

Compliance with Ethics Guidelines. The study was approved by the institutional research review board (post-graduate research review board of SMS Medical College, Jaipur, India) and was conducted following the approved protocol and ethical principles that have their origin in the Declaration of Helsinki. Written informed consent was obtained from each patient before enrolment.

Data Availability. The datasets generated during and/or analyzed during the current study are available from the corresponding author on reasonable request.

Open Access. This article is licensed under a Creative Commons Attribution-NonCommercial 4.0 International License, which permits any non-commercial use, sharing, adaptation, distribution and reproduction in any medium or format, as long as you give appropriate credit to the original author(s) and the source, provide a link to the Creative Commons licence, and indicate if changes were made. The images or other third party material in this article are included in the article's Creative Commons licence, unless indicated otherwise in a credit line to the material. If material is not included in the article's Creative Commons licence and your intended use is not permitted by statutory regulation or exceeds the permitted use, you will need to obtain permission directly from the copyright holder. To view a copy of this licence, visit http://creativecommons.org/licenses/by$\mathrm{nc} / 4.0 /$.

\section{REFERENCES}

1. World Health Organization. Global health observatory (GHO) data: HIV/AIDS. Available from: https://www.who.int/gho/hiv/en/; Accessed on 18. 05.2020

2. Walker-Bone K, Doherty E, Sanyal K, Churchill D. Assessment and management of musculoskeletal disorders among patients living with HIV. Rheumatology (Oxford). 2017;56(10):1648-61. https://doi.org/10.1093/rheumatology/kew418.

3. https://www.avert.org/professionals/hiv-aroundworld/asia-pacific/india. Accessed 18 May 2020.

4. Winchester R, Bernstein D, Fischer H, Enlow R, Solomon G. The co-occurrence [3] of Reiter's syndrome and acquired immunodeficiency. Ann Intern Med. 1987;106:19-26. https://doi.org/10.7326/ 0003-4819-106-1-19.

5. Medina-Rodriguez F, Guzman C, Jara LJ, Hermida C, Alboukrek D, Cervera $\mathrm{H}$, et al. Rheumatic manifestations in human immunodeficiency virus-positive and negative individuals: a study of 2 populations with similar risk factors. J Rheumatol. 1993;20(11):1880-4. 
6. Berman A, Espinoza LR, Diaz JD, Aguilar JL, Rolando T, Vasey F, et al. Rheumatic manifestations of human immunodeficiency virus infection. Am J Med. 1988;85(1):59-64.

7. Narayanan K, Batra RB, Anand KP. Rheumatic manifestations of HIV infection. Indian J Rheumatol. 2008;3(1):4-7.

8. Zhang X, Li H, Li T, Zhang F, Han Y. Distinctive rheumatic manifestations in 98 [6] patients with human immunodeficiency virus infection in China. J Rheumatol. 2007;34(8):1760-4.

9. Kutty Krishnan K, Panchapakesa RC, Porkodi R, Madhavan R, Ledge SG, Mahesh A. Rheumatological manifestations in HIV positive patients referred to a tertiary care centre. J Indian Rheumatol Assoc. 2003;11:104-8.

10. Reveille John D. Rheumatic manifestations of Human immunodeficiency virus infection. Kelley's Textbook of Rheumatology, vol. 2. 6th ed. Philadelphia: Saunders; 2001. pp. 1507-18.

11. Kutty Krishnan K, Panchapakesa RC, Porkodi R, Madhavan R, Ledge SG, Mahesh A. Rheumatological manifestations in HIV positive patients referred to a tertiary care center. J Indian Rheumatol Assoc. 2003;11:104-8.

12. Calabrese LH. Human immunodeficiency virus (HIV) infection and arthritis. Rheum Dis Clin North Am. 1993;19:477-88.

13. Kumaryadav P, Jayakumar B. Clinical spectrum of rheumatologic manifestations in HIV patients: A Study from Southern India. J Clin Diag Res. 2019;13(8):OC01-OC03.

14. Kaddu-Mukasa M, Ssekasanvu E, Ddumba E, Thomas D, Katabira ET. Rheumatic manifestations among HIV positive adults attending the Infectious disease clinic at Mulago hospital. Afri Health Sci. 2011;11(1):24-9.

15. Casado E, Tena X, Olive ÂA. HIV infection-associated rheumatic syndromes. Clin Exp Rheumatol. 1999;17:633.

16. Blanche P, Sicord D, Saraux A, Taelman H. Arthritis and HIV infection in Kigali, Rwanda, and Paris. France J Rheumatol. 1997;24:1149-50.

17. Cuellar ML, Espinoza LR. Rheumatic manifestations of HIV-AIDS BaillieÁre's. Clin. Rheumatol. 2000;14(3):579-93.

18. Casado E, Olivé A, Holgado S, Perez-Andres R, Romeu J, Lorenzo JC, Clotet B, Tena X. Musculoskeletal manifestations in patients positive for human immunodeficiency virus: correlation with CD4 count. J Rheumatol. 2001;28(4):802-4.

19. Calabrese LH, Kelley DM, Myers A, O'connell M, Easley K. Rheumatic symptoms and human immunodeficiency virus infection. Arthr Rheumat. 1991;34(3):257-63.

20. Santa N, Arvind G, Bimol N, Bhagyabati Devi S. Prevalence of rheumatic manifestations in HIV patients: a cross-sectional study from Manipur, India. IJRCI. 2017;5(1):OA3.

21. Munoz Fernandez S, Cardenal A, Balsa A, Quiralte J, del Arco A, Pena JM, Barbado FJ, Vazquez JJ, Gijon J. Rheumatic Manifestations in 556 Patients With Human Immunodeficiency Virus Infection. Sem Arthr Rheumat. 1991;21(1):30-9.

22. Berman A, Reboredo G, Spindler A, et al. Rheumatic manifestations in populations at risk for HIV infection: the added effect of HIV. J Rheumatol. 1991;18:1564-7.

23. Kole AK, Roy R, Kole DC. Musculoskeletal and rheumatological disorders in HIV infection: experience in a tertiary referral center. Indian J Sex Transm Dis AIDS. 2013;34(2):107-12.

24. Achuthan K, Uppal SS. Rheumatological manifestations in 102 cases of HIV infection. JIRA. 1996;3: $43-7$.

25. Buskila D, Gladman DD, Langevitz P, Bookman AA, Fanning M, Salit IE. Rheumatologic manifestations of infection with the human immunodeficiency virus (HIV). Clin Exp Rheumatol. 1990;8(6):567-73.

26. Rogeaux O, Fassin D, Gentilini M. Prevalence of Rheumatic manifestations in human immunodeficiency virus infection. Ann Med Interne (Paris). 1993;144(7):443-8.

27. Reveille JD, Conant MA, Duvic M. Human immunodeficiency virus-associated psoriasis, psoriatic arthritis, and Reiter's syndrome: a disease continuum? Arthritis Rheum. 1990;33(10):1574-8.

28. Ornstein $M H$, Kerr LD, Spiera $H$. A reexamination of the relationship between active rheumatoid arthritis and the acquired immunodeficiency syndrome. Arth Rheum. 1995;38:1701-6.

29. Espinoza LR, Jara LJ, Espinoza CG, et al. There is an association between human immunodeficiency virus infection and spondyloarthropathies. Rheum Dis Clin North Am. 1992;18:257-66.

30. Rivera J, Garcia-Monforte A. Human immunodeficiency virus infection and arthritis. J Rheumatol. 2000;27(5):1322-3. 
31. Cuellar ML, Espinoza LR. Human immunodeficiency virus associated spondyloarthropathy: lessons from the Third World. J Rheumatol. 1999;26: 2071-3.

32. Kaye BR. Rheumatologic manifestations of infection with human immunodeficiency virus (HIV). Ann Intern Med. 1989;111(2):158-67. https://doi. org/10.7326/0003-4819-111-2-158.

33. Francisco MedinaRodriguez MD. Rheumatic manifestations of human immunodeficiency virus infection. Rheum Dis Clin North Am. 2003;29(1):145-61.

34. Bohra V, Shanmuganandan K. The spectrum of rheumatic manifestations of HIV Infection in an era of antiretroviral therapy. Indian $\mathrm{J}$ Rheumatol. 2011;6(1):28-37.

35. Espinoza LR, Berman A. Soft tissues and osteo-articular infections in HIV-infected patients and other immunodeficient states. Best Pract Res Clin Rheumatol. 1999;13:115-28.

36. Marquez J, Restrepo CS, Candia L, Berman A, Espinoza LR. Human immunodeficiency virus- associated rheumatic disorders in the HAART era. J Rheumatol. 2004;31(4):741-6.

37. D McGonagle, S Reade, H Marzo-Ortega, W Gibbon, P O'Connor, A Morgan, R Melsom, E Morgan, P Emery Human immunodeficiency virus associated spondyloarthropathy: pathogenic insights based on imaging findings and response to highly active antiretroviral treatment. Ann Rheum Dis 2001;60 (7):696-8.

38. Reveille JD. The changing spectrum of rheumatic disease in human immunodeficiency virus infection. Semin Arthritis Rheum. 2000;30(3):147-66.

39. Berman A, Reboredo G, Spindler A, Lasala ME, Lopez H, Espinoza LR. Rheumatic manifestations in populations at risk for HIV infection: the added effect of HIV. J Rheumatol. 1991;18(10):1564-7.

40. Berman A, Cahn P, Perez H, Spindler A, Lucero E, Paz S, Espinoza LR. Human immunodeficiency virus infection associated arthritis: clinical characteristics. J Rheumatol. 1999;26(5):1158-62. 